\title{
Association of posterior EEG alpha with prioritization of religion or spirituality: A replication and extension at 20-year follow-up
} \author{
Gerard E. Bruder ${ }^{a, b, c}$ \\ a Division of Cognitive Neuroscience, NYS Psychiatric Institute, New York, NY, United States \\ b Division of Epidemiology, NYS Psychiatric Institute, New York, NY, United States \\ ${ }^{\mathrm{c}}$ Department of Psychiatry, Columbia University, College of Physicians and Surgeons, New York, NY, United States \\ d Columbia University, Teachers College, New York, NY, United States \\ e Columbia University, Mailman School of Public Health, New York, NY, United States
}

Craig E. Tenke ${ }^{\mathrm{a}, \mathrm{b}, \mathrm{c}, *}$, Jürgen Kayser ${ }^{\mathrm{a}, \mathrm{b}, \mathrm{c}}$, Connie Svob ${ }^{\mathrm{b}, \mathrm{c}}$, Lisa Miller $^{\mathrm{c}, \mathrm{d}}$, Jorge E. Alvarenga ${ }^{\mathrm{a}}$, Karen Abraham ${ }^{\mathrm{a}}$, Virginia Warner ${ }^{\mathrm{b}, \mathrm{e}}$, Priya Wickramaratne ${ }^{\mathrm{b}, \mathrm{c}, \mathrm{e}}$, Myrna M. Weissman $^{\mathrm{b}, \mathrm{c}, \mathrm{e}}$,

\section{A R T I C L E I N F O}

\section{Article history:}

Received 2 August 2016

Received in revised form

10 December 2016

Accepted 15 January 2017

Available online 22 January 2017

\section{Keywords:}

EEG alpha

Religion and spirituality

Current source density (CSD)

Principal components analysis (PCA)

Depression risk

Development

\begin{abstract}
A B S T R A C T
A prior report (Tenke et al., 2013 Biol. Psychol. 94:426-432) found that participants who rated religion or spirituality (R/S) highly important had greater posterior alpha after 10 years compared to those who did not. Participants who subsequently lowered their rating also had prominent alpha, while those who increased their rating did not. Here we report EEG findings 20 years after initial assessment. Clinical evaluations and $\mathrm{R} / \mathrm{S}$ ratings were obtained from 73 ( 52 new) participants in a longitudinal study of family risk for depression. Frequency PCA of current source density transformed EEG concisely quantified posterior alpha. Those who initially rated $\mathrm{R} / \mathrm{S}$ as highly important had greater alpha compared to those who did not, even if their R/S rating later increased. Furthermore, changes in religious denomination were associated with decreased alpha. Results suggest the possibility of a critical stage in the ontogenesis of $R / S$ that is linked to posterior resting alpha.
\end{abstract}

(C) 2017 Elsevier B.V. All rights reserved.

\section{Introduction}

Prominent EEG alpha, which is typically obtained from surface potentials measured at scalp, has been associated with better pharmacologic treatment outcomes for clinical depression (Bruder et al., 2008; Tenke et al., 2011; Ulrich, Renfordt, \& Frick, 1986). However, systematic comparisons of resting alpha for reference-dependent (nose, average) EEG with reference-free surface Laplacian or current source density (CSD) transformations have demonstrated considerable pitfalls for spectra derived from surface potentials (SP) that are effectively counteracted by CSD (Kayser \& Tenke, 2006a, 2006b, 2015a, 2015b; Tenke \& Kayser, 2005, 2015). Compared to SP spectra, CSD spectra not only have sharper topographies (Tenke et al., 2015) but also provide the more consistent and appropriate representation of distributed posterior generators in simulation (Tenke \& Kayser, 2015), and thereby yield more reliable estimates

\footnotetext{
* Corresponding author at: Division of Cognitive Neuroscience, NYS Psychiatric Institute, 1051 Riverside Drive, New York, NY, United States. Tel.: +1 6467745222. E-mail address: cet2103@cumc.columbia.edu (C.E. Tenke).
}

of alpha activity at scalp. We found that overall posterior CSD alpha during rest is strongly correlated with prestimulus alpha in a novelty oddball task (Tenke et al., 2015), suggesting that posterior alpha may reflect a stable individual trait that cuts across task boundaries or experimental protocols. Even though posterior alpha has been associated with a family history of MDD (Bruder et al., 2005), it remains to be determined to what extent posterior alpha is (1) related to a vulnerability to depression, (2) a predictor of treatment outcome, or (3) an initial vulnerability that is linked to a subsequent propensity toward recovery.

The personal importance of religion or spirituality $(\mathrm{R} / \mathrm{S})$ is associated with protection against depression (Kendler, Gardner, \& Prescott, 1997; Miller, Warner, Wickramaratne, \& Weissman, 1997; Smith, McCullough, \& Poll, 2003), and particularly against recurrence of depression (Miller et al., 2012), which is consistent with an acquired resilience following initial vulnerability to MDD. We previously observed that individuals who differed by personal importance of $\mathrm{R} / \mathrm{S}$ also differed in the prominence of EEG alpha (Tenke et al., 2013) suggesting that prominent alpha may be a marker for a cluster of related biological, affective and hedonic pre- 
dispositions. Those who rated $\mathrm{R} / \mathrm{S}$ as important at an initial test session had greater EEG alpha at a subsequent assessment ten years later than those who did not (Tenke et al., 2013). Our initial considerations led us to hypothesize that EEG alpha might increase in amplitude as a result of $\mathrm{R} / \mathrm{S}$ importance. In this scenario, alpha enhancement could be a result of meditation or prayer (Aftanas \& Golosheykin, 2005; Cahn \& Polich, 2006; Chiesa \& Serretti, 2010), stress reduction (Flannelly, Koenig, Galek, \& Ellison, 2007; Koenig, 2009; Meisenhelder \& Marcum, 2009; Stein et al., 2004), or other practices that might accompany R/S. However, our EEG findings were inconsistent with this interpretation, because we observed neither the enhancement of alpha with newly acquired R/S importance, nor its disappearance when the valuation of R/S decreased.

Another conclusion that might be drawn from the data is that EEG alpha could be a marker for the ontogenesis and time course of a disposition toward $\mathrm{R} / \mathrm{S}$, rather than either a result or correlate of $\mathrm{R} / \mathrm{S}$ itself. However, this simpler conclusion is at best preliminary, because the data were limited to changes in $\mathrm{R} / \mathrm{S}$ Importance assessed at the same time point at which the EEG was measured. It was thereby possible that hypothesized changes in EEG alpha simply required additional time to develop. Conversely, prominent alpha could itself be the trait that protects against MDD and/or is predictive of a good treatment response, and that individuals with this trait disproportionately value R/S highly. Apart from these conceptual considerations, an additional limitation of the original study was a limited spatial sampling of the alpha topography with a low-density EEG montage (i.e., 13 sites), which might have underrepresented the complete posterior generator topography of alpha.

The purpose of the present study was to replicate and extend the previous findings on R/S and EEG alpha. After an additional ten year interval, a larger sample of participants were administered two additional R/S assessments and an EEG recording using a higher density montage (i.e., 72 sites) to better captures the generator topography of EEG alpha. The additional assessments over time allowed us to distinguish between two competing hypotheses: (1) those who were initially identified as having high R/S importance would continue to show high alpha, regardless of intervening $R / S$ reports (i.e. the initial $\mathrm{R} / \mathrm{S}$ distinguished between individuals differing in the trait of EEG alpha); or (2) individuals who increased, and subsequently maintained, their self-reports of $\mathrm{R} / \mathrm{S}$ importance would also develop high amplitude alpha (i.e. prominent alpha is associated with persistent $\mathrm{R} / \mathrm{S}$ importance).

\section{Methods}

\subsection{Participants}

This report included seventy-three adult participants (43 female) who had EEG recordings at year 30 (T30; mean age 43.25 yrs \pm 10.2 ) as part of a multiwave three-generation longitudinal study of individuals at high and low risk for major depression based on family history (for details of methods see Weissman, Warner, Wickramaratne, Moreau, \& Olfso, 1997; Weissman et al., 2005; Weissman et al., 2006; Weissman et al., 2016a, 2016b). Twenty-one participants were also included in our previous report of the findings at T20 (Tenke et al., 2013), while the remaining 53 only had EEG data at T30. In the original wave of the study (Weissman et al., 1997), probands with moderate to severe major depressive disorder were selected from outpatient clinics for the psychopharmacologic treatment of mood disorders, and nondepressed, demographically-matched control participants were selected from an epidemiologic sample of adults with no psychiatric history from the same community. The sample was recruited from an urban setting (greater New Haven area, Connecticut, US), and consisted of Caucasian and working or middle class individuals.
Table 1

Lifetime MDD by Parental MDD.

\begin{tabular}{llll}
\hline & \multicolumn{2}{l}{ Lifetime MDD } & \\
\cline { 2 - 3 } & No & Yes & 27 \\
No MDD Parent & 18 & 9 & 46 \\
MDD Parent & 13 & 33 & 73 \\
\hline
\end{tabular}

Fisher's exact test: $\mathrm{p}=.003$.

Table 2

Religious Denomination.

\begin{tabular}{lll}
\hline & T10 & T30 \\
\hline Catholic & 47 & 37 \\
Protestant & 10 & 5 \\
Jewish & 4 & 4 \\
Buddhist/Hindu/Islam & - & 1 \\
Personal Religious & 2 & 13 \\
Agnostic/Atheist & 4 & 8 \\
Other & - & 5 \\
& $N=67$ & $N=73$ \\
\hline
\end{tabular}

Clinical assessments were conducted by independent interviewers who were blind to the participant's previous clinical history (personal or family).

Assessments were from waves at years 10 (T10; beginning 1992), 20 (T20; beginning 2002), 25 (T25) and 30 (T30). All procedures had been approved by the institutional review boards at Yale University and at Columbia University/New York State Psychiatric Institute. All participants gave written informed consent. As indicated in Table 1, 46 participants who were at high risk due to parental depression were also characterized by significantly greater lifetime rates of MDD compared to those in the low risk group (Fisher exact test, $\mathrm{p}=.003$ ).

\subsection{Religiosity or spirituality}

Assessments included participant responses on religious denomination and attendance ("never" to "once a week or more" on a 5-point scale) at T10, T20, T25 and T30. As indicated in Table 2, participants were predominantly Roman Catholic (70\%) when first assessed at T10, which dropped to $51 \%$ by T30. A total of $44 \%$ of the participants reported a change in religious denomination during this time span. $\mathrm{R} / \mathrm{S}$ importance was also assessed with the question "How important is religion or spirituality to you?" Response option ranged from 1 to 4 ("not important at all," "slightly important," “moderately important," "very important"). This question showed robust correlations with the widely-used Fetzer Institute full-scale measure of personal spirituality (Idler et al., 2003). The terms "religion" and "spirituality" were both included in this question because they are frequently linked together in studies on health (Koenig, McCullough, \& Larson, 2001; Larson \& Larson, 2003; Tsuang, Williams, Simpson, \& Lyons, 2002). Participant responses were dichotomized as "very important" vs. all other responses based on prior findings (Miller et al., 1997, 2012; Tenke et al., 2013), and will hereafter be referred to as "Important" and "Not Important" for sake of brevity.

Table 3 shows the $\mathrm{R} / \mathrm{S} / \mathrm{Importance}$ classification of all participants at assessment time T10 and the later assessments, indicating subgroup classifications (italics) and corresponding cell sizes for the resulting subgroups and the cross-tabulation marginals (row and column sums). Only 21 participants provided EEG at wave 20 (ns in parentheses). Of the 73 in the present sample, 14 were categorized as "Important" at T10. All except 4 of these changed their prioritization at a later assessment (i.e., they "Migrated Out" of their prioritization). However, the total number who prioritized 
Table 3

Subgroups for Prioritizing of R/S Importance at Initial (T10) vs. Later Assessment ( $\geq \mathrm{T} 20$ ).

\begin{tabular}{|c|c|c|c|c|}
\hline & & \multicolumn{2}{|c|}{ Later Assessment (T20, T25, T30) } & \multirow[b]{2}{*}{ T10 Totals } \\
\hline & & Important & Not Important & \\
\hline \multirow[t]{3}{*}{$\mathrm{T} 10$} & Important & $\begin{array}{l}\text { Always } \\
n=4(2)\end{array}$ & $\begin{array}{l}\text { Migrate Out } \\
n=10(2)\end{array}$ & $\begin{array}{l}\text { Always/Migrate Out } \\
n=14 \text { (4) }\end{array}$ \\
\hline & Not Important & $\begin{array}{l}\text { Migrate In } \\
n=23\left(8^{*}\right)\end{array}$ & $\begin{array}{l}\text { Never } \\
n=36(9)\end{array}$ & $\begin{array}{l}\text { Migrate In/Never } \\
n=59(17)\end{array}$ \\
\hline & $\begin{array}{l}\text { Later Assessment } \\
\text { Totals }\end{array}$ & $\begin{array}{l}\text { Always/Migrate In } \\
n=27 \text { (10) }\end{array}$ & $\begin{array}{l}\text { Migrate Out/Never } \\
n=46(14)\end{array}$ & $N=73(21)$ \\
\hline
\end{tabular}

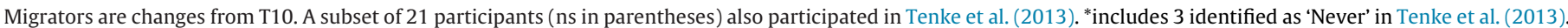

$\mathrm{R} / \mathrm{S}$ as Important at any assessment increased to 37 including 23 participants initially classified as "Not Important" at T10 (i.e., they "Migrated In"). The remaining 36 were stable in their expression of faith as "Not Important" (i.e., "Never"). To be consistent with the classification used in Tenke et al. (2013), comparisons will be made for these four major subgroupings (Always, Migrated Out, Migrated In, Never), or after collapsing Always and Migrated Out.

Table 4 dissects the composition of these subgroupings by familial risk, gender, and lifetime MDD, with bolded labels reflecting the number of participants included for testing the primary hypotheses (i.e., Important at T10, Migrate In and Never). Women were no more likely than men to rate $\mathrm{R} / \mathrm{S}$ as "Important" at any assessment (Always plus Migrate Out plus Migrate In; 21 out of 44 vs. 11 out of 29; Fisher exact test, two-sided, $n s$ ). Likewise, neither risk of MDD due to family history nor lifetime history of MDD distinguished between these three major groupings.

\subsection{EEG methods}

Resting EEG was measured while participants sat quietly during four 2-min periods (order of eyes-open and eyes-closed counterbalanced across participants and assessments) after being instructed to avoid blinking and eye and body movements (fixation cross used for eyes-open condition; e.g., cf. Tenke et al., 2011). Continuous data were acquired at 256 samples/s using a 24-bit EEG recording system (BioSemi, Inc., 2001) with a 72-channel 10/10system scalp montage (Jurcak, Tsuzuki, \& Dan, 2007; Pivik et al., 1993 ) including the nose. Data were blink-corrected offline using a spatial, singular value decomposition (NeuroScan, Inc., 2003), and segmented into 2 -s epochs (75\% overlap). Epoched data were screened for electrolyte bridges (Alschuler, Tenke, Bruder, \& Kayser, 2014; Tenke \& Kayser, 2001), and affected channels interpolated via spherical splines (Perrin, Pernier, Bertrand, \& Echallier, 1989). Channels containing artifacts or noise for any given trial were identified using a reference-free approach to identify isolated EEG channels containing amplifier drift, residual eye activity, muscle or movement-related artifacts for any given trial (Kayser \& Tenke, 2006b), which were then replaced by spherical spline interpolations (Perrin et al., 1989) from artifact-free channels (i.e., if fewer than $25 \%$ of all channels contained artifact). Artifact detection and electrode interpolation was verified interactively. Finally, epochs exceeding $\pm 100 \mu \mathrm{V}$ in any channel (including uncorrected EOG) were rejected to conform to conventional methods.

\subsection{Quantification of posterior alpha generators}

Artifact-free EEG epochs were transformed to CSD using a spherical spline Laplacian (spline flexibility constant $m=4$, regularization constant $\lambda=10^{-5}, 50$ iterations; Perrin et al., 1989; Kayser \& Tenke, 2006b, 2015b; cf. Kayser, 2009). The DC offset of each epoch was removed, the EEG was tapered over the entire 2-s duration using a Hanning window (Bendat \& Piersol, 1971), and padded with zeros ( $1 \mathrm{~s}$ at each end). The CSD power spectrum resolution obtained from a subsequent FFT was thereby $0.25 \mathrm{~Hz}$ (NeuroScan, Inc., 2003), which is consistent with Tenke et al. (2011); 1-s epochs padded to $4 \mathrm{~s} ; 1024$ points/epoch) although with less spectral interpolation. CSD amplitude spectra (square root of power spectra; Tenke \& Kayser, 2005) were submitted to unrestricted, covariance-based frequency PCA (fPCA) followed by Varimax rotation of the loadings (Kayser \& Tenke, 2003).

Fig. 1 shows the first four CSD-fPCA factors, comprising $85 \%$ of the CSD variance, with all remaining factors accounting for less than 4\%. Low- and high-frequency alpha factors were unambiguously identifiable by their spectral loadings waveforms and their condition-related topographies (Tenke \& Kayser, 2005, 2015; Tenke et al., 2011, 2015). These factors were subsequently pooled over their posterior maxima over each hemisphere (low-frequency alpha, right hemisphere: PO10, PO8, P8; high-frequency, right hemisphere: PO8, PO4, O2, POz, Oz; homologous sites for left hemisphere).

\subsection{Statistical method}

The analysis strategy precisely followed that used in our previous study of EEG and R/S (Tenke et al., 2013). Posterior alpha CSD was compared using a repeated measures ANOVA with alpha Factor (high-frequency alpha, low-frequency alpha), Hemisphere (left, right) and Condition (eyes-open, eyes-closed) as within-subject factors and Importance at T10 (Important, Not Important) as the primary grouping factor. Between-subjects variables of Gender (male, female), Parental Depression (no parental MDD, parental MDD), and Lifetime Depression (MDD, No MDD) were also included as control design factors, and age at the T30 EEG session was used a covariate. Previous CSD-fPCA findings have not suggested important distinctions between the two posterior alpha factors as related to MDD treatment response (Tenke et al., 2011) or R/S importance (Tenke et al., 2013). Consequently, effects involving Factor were not specifically probed (but see Table S1 in Supplementary Material).

Additional analyses followed directly from the findings of Tenke et al. (2013). In particular, Always Important and Migrate Out were collapsed into a single group, owing to the observation that both groups had greater alpha compared to Migrate In, and because of the small number of Always Important participants. Likewise, ANOVA models were supplemented by distribution-free statistics (MannWhitney $U$ ) to compare overall (mean across conditions) and net (difference between conditions) alpha between the same groups. Finally, participants were classified as having high or low overall alpha amplitude based on the median for those who never reported R/S as important (Tenke et al., 2013). The resulting contingency tables were compared using a Fisher exact test.

Inasmuch as religious concordance within families has itself been linked to protection against MDD (Jacobs, Miller, Wickramaratne, Gameroff, \& Weissman, 2012; Miller et al., 1997), significant findings involving religious importance were followed up by repeated measures ANOVA directly comparing the two Migrator Groups (Migrate Out, Migrate In), with Denomination Change 
Table 4

Characteristics of Importance Subgroups.

\begin{tabular}{|c|c|c|c|c|c|c|c|}
\hline & \multirow[t]{2}{*}{$n$} & \multicolumn{2}{|c|}{ Parent MDD } & \multicolumn{2}{|l|}{ Gender } & \multicolumn{2}{|c|}{ Lifetime MDD } \\
\hline & & No & Yes & Female & Male & No & Yes \\
\hline Important at T10 & 14 & 5 & 9 & 8 & 6 & 5 & 9 \\
\hline Always & 4 & 1 & 3 & 2 & 2 & 1 & 3 \\
\hline Migrate Out & 10 & 4 & 6 & 6 & 4 & 4 & 6 \\
\hline Not Important at T10 & 59 & 22 & 37 & 36 & 23 & 26 & 33 \\
\hline Migrate In & 18 & 8 & 10 & 13 & 5 & 8 & 10 \\
\hline \multirow[t]{2}{*}{ Never } & 41 & 14 & 27 & 23 & 18 & 18 & 23 \\
\hline & 73 & 27 & 46 & 44 & 29 & 31 & 42 \\
\hline
\end{tabular}

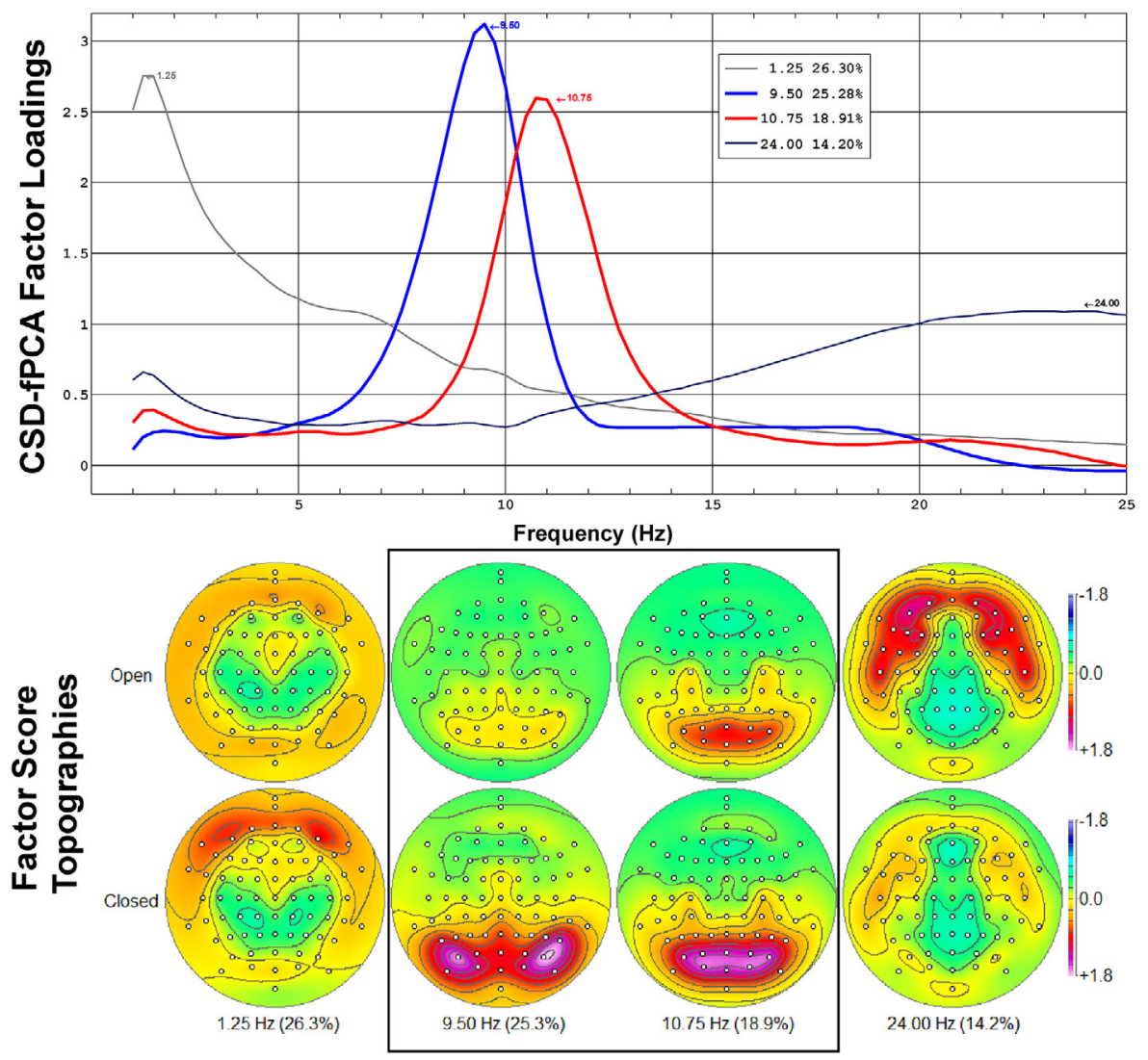

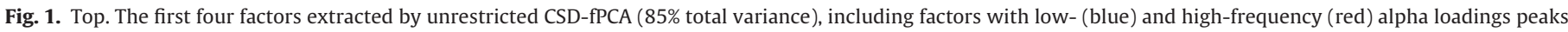

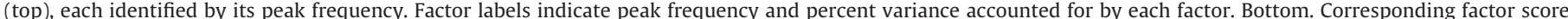

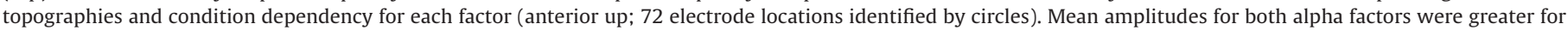

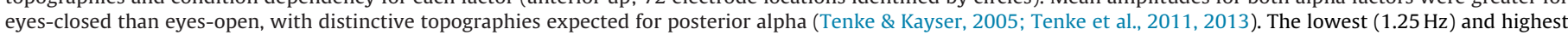

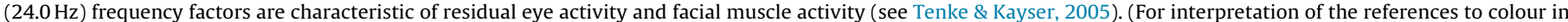
this figure legend, the reader is referred to the web version of this article.)

(changed, not changed), and Gender as additional grouping factors, and with age and attendance at T30 as a covariates.

\section{Results}

The repeated measures ANOVA model for Importance at T10 (Always/Migrate Out vs Migrate In/Never) revealed a Group main effect $(F[1,58]=5.20 ; p=.026)$, owing to significantly greater overall posterior EEG alpha for the Always/Migrate Out group. This difference is prominently illustrated by the overall mean factor score topographies shown in Fig. 2, where Always/Migrate Out (Important at T10) group has the greatest alpha. The ANOVA for these three groupings supports this observation with a marginally significant Importance main effect $(\mathrm{F}[2,51]=3.063 ; \mathrm{p}=.055)$, and a significant Condition x Parental Depression x Lifetime Depression interaction $(\mathrm{F}[1,51]=6.337, \mathrm{p}=.015) .{ }^{1}$ The Condition main effect was robust, as expected (greater alpha for eyes-closed than eyesopen; $F[1,51]=9.889, p=.003$; cf. Fig. 1 ).

Fig. 3 shows the scatter plot of overall alpha factor score amplitude for each of the R/S subgroupings. Alpha amplitude was greatest for Always/Migrate Out (i.e., those reporting R/S important at T10). Notably, the two Migrate Out participants who resumed their high valuation of R/S importance by T30 (green triangles) had no greater overall alpha than those who did not. In contrast, Migrate In participants generally showed low overall alpha amplitude, regardless of whether their acquired importance persisted (blue triangles)

\footnotetext{
1 ANOVA interactions were observed involving Factor (high frequency alpha, low frequency alpha) and Gender (male, female). These are presented as supplementary material (Table S1) and will not be further discussed in this report.
} 


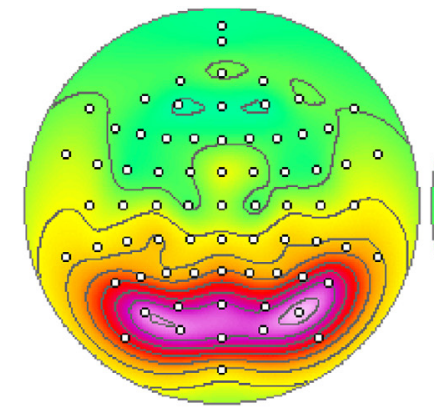

Always/Migrate Out (14)

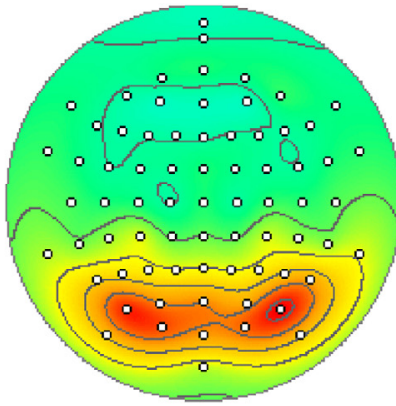

Migrate In (23)

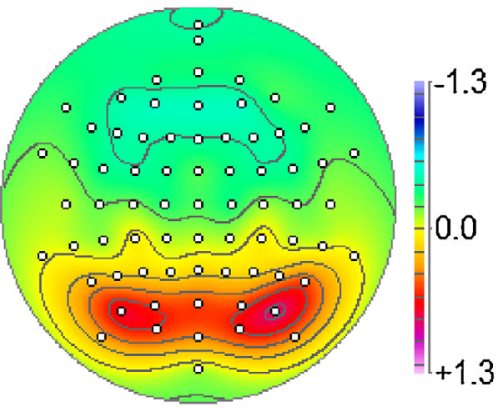

Never (36)

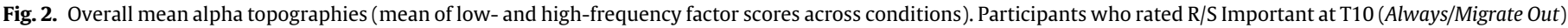

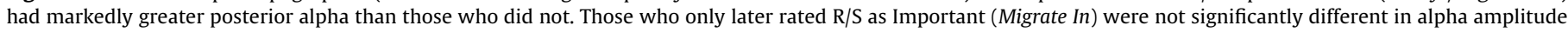

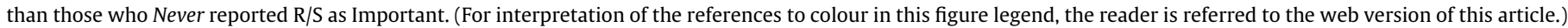

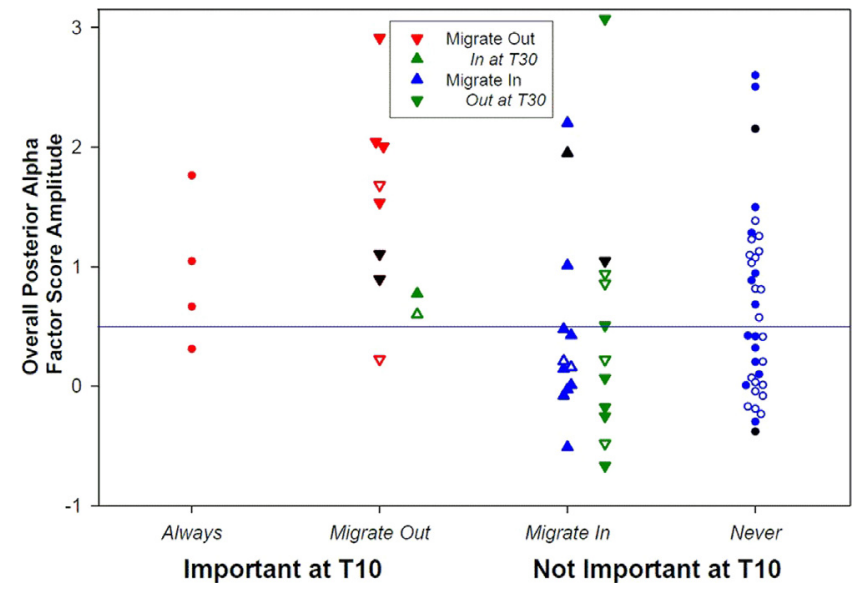

Fig. 3. Scatterplot of overall posterior CSD alpha (pooled across Alpha Factor, Condition, Hemisphere and Site) for individuals in each of the R/S Importance subgroups. The horizontal line reflects the median for those who Never reported R/S as Important. Alpha was greater for individuals reporting R/S as "Important at T10" than for those reporting “Not Important at T10." Those who continued to report R/S as Important (Always) were indistinguishable from those who Migrate Out at one or more later assessments. Although individuals who Migrate In after T10 included participants with very low overall alpha, some cases spanned the alpha range of Always and Migrate Out. Neither the recency nor the persistence of an Importance rating were associated with prominent overall alpha for the Migrate In group. Individuals who Migrate Out at T20-T30 are indicated by red downward arrows unless they also reported R/S as Important at T30 (green upward arrows). Likewise, those who Migrate In at T20-T30 are indicated by blue upward arrows unless they also reported R/S as Not Important at T30 (green downward arrows). Open symbols: denomination change between T10 and T30; Black symbols: T10 denomination missing.

or was lost by T30 (green inverted triangle). Consequently, the difference between Always/Migrate Out and Migrate In is robust (Mann-Whitney $\mathrm{U}=68, \mathrm{~N}=37, \mathrm{p}=.003$ ), as is the contingency table using the Never median as a classification threshold (Fisher 2-tailed exact test $\mathrm{p}=.006$ ).

Also evident in Fig. 3 is the observation that of those who reported $\mathrm{R} / \mathrm{S}$ as important at any time, the five individuals with the highest amplitude alpha were the Migrators who retained their religious denomination (filled symbols). The difference in alpha due to denomination change was evaluated by a repeated measures ANOVA with Denomination Change (changed, not changed), Migrator Group (Migrate In, Migrate Out) and Gender as between-subject factors and age and attendance as covariates, yielding a significant effect of Denomination Change $(\mathrm{F}[1,19]=5.061, \mathrm{p}=.037)$. Moreover, a condition-dependent difference between migrator groups was observed (Condition x Migrator Group interaction, F[1,19]=6.152, $\mathrm{p}=.023$ ) in further qualification of a marginally significant overall Migrator Group main effect $(\mathrm{F}[1,19]=3.961$, $\mathrm{p}=.061)$.

\section{Discussion}

\subsection{EEG alpha and R/S importance: replication and extension}

These findings provide additional support for the linkage between the timecourse of personal R/S importance that unfolds over a lifetime and a persistent individual trait of prominent posterior EEG alpha. The present report extends the time scale of this linkage by an additional ten years in a larger, mostly independent sample of participants. Moreover, by virtue of using a substantially denser EEG montage (72 vs. 13 sites), the effects could be unequivocally matched to the unique neuronal generator pattern identified with posterior EEG alpha (Tenke et al., 2011, 2015).

These findings closely parallel those reported for the T20 EEG sample (Tenke et al., 2013). Individuals who initially (T10) reported a high personal importance of R/S had significantly greater posterior resting EEG alpha when measured twenty years later (T30). In contrast, those who only later reported a high personal R/S importance (Migrate $I n$ ) were characterized by low amplitude alpha. Although these differences were quite robust, the Migrate In group for the present sample included a number of individuals with high amplitude alpha (8/23 greater than Never median), as compared to substantially fewer (2/12) in the previous study (Tenke et al., 2013).

The number of participants included in both the present and the previous study (Tenke et al., 2013; i.e., EEG recorded at both T20 and T30) and who reported R/S as Important at T10 was quite small (Table 3, $n=4$ ). However, data from a considerably larger sample with EEG at both assessments (T20 and T30 EEG; alpha comparisons based on the smaller montage) revealed a strong test-retest correlation for overall posterior alpha (Tenke et al., submitted). The evidence is therefore quite strong that R/S Importance at T10 uniquely identifies an individual as having prominent overall EEG alpha independent of any subsequent changes in personal evaluation of R/S Importance.

A sizeable subsample of Migrate In participants again changed their appraisal of R/S importance by T30 (Fig. 3, those Migrate In who migrated out again at T30 [green inverted triangles]). These cases consistently had low amplitude alpha, with only one exception. However, while there were only two Migrate Out cases that changed again (Migrate Out who migrated in again at T30 [green triangles]), and neither one had exceptionally high amplitude alpha. Collectively, there is little evidence that the persistence or recency of $\mathrm{R} / \mathrm{S}$ importance has any impact on posterior alpha. However, migrators with the greatest alpha were those with a stable religious denomination (solid symbols). Inasmuch as concordance of denomination across generations is also protective against depression (Miller et al., 1997; Jacobs et al., 2012), a possible association 
between religious discord and (low) alpha cannot be ruled out. Further inferences cannot be drawn given the limited sample sizes.

\subsection{Individual differences in EEG alpha}

EEG alpha is characteristically produced in states of relaxed wakefulness with reduced sensory stimulation (Gloor, 1969), which provides the rationale for applying net alpha (eyes closed minus eyes open) as a measure of deactivation (Bruder et al., 1997; Henriques \& Davidson, 1990). Not surprisingly, structured meditation practice has been shown to increase EEG alpha (Cahn \& Polich, 2006), suggesting that meditation and compatible forms of prayer share a physiological basis with relaxation and disengagement. Conversely, focused attention or stress-related processes are consistent with alpha blocking. This conceptualization implies that a continuum exists for alpha connecting behavioral states with minimal demands, such as the eyes-open/closed resting EEG, to those in more demanding tasks. However, there are substantial individual differences in EEG alpha (e.g., Klimesch, 1999). While some individuals show appreciable alpha during relatively difficult tasks, others may produce minimal or no alpha while relaxing with eyes closed. These limiting conditions (i.e. floor and ceiling effects) offer at least a partial explanation for the observation that prestimulus task-related alpha (auditory novelty oddball) was strongly correlated with overall resting alpha, but negatively correlated with net resting alpha (Tenke et al., 2015). This distinction is particularly important because early R/S Importance was an indicator for overall alpha, rather than net alpha, in this and our previous study (Tenke et al., 2013).

\subsection{Religious denomination, $R / S$ importance and EEG alpha}

The impact of denomination change on posterior resting alpha could have a simple origin. Inasmuch as Migrators view, or have viewed, $\mathrm{R} / \mathrm{S}$ as very important, a change in denomination has the capacity to index a stressful life event with implications beyond personal R/S. These implications can include familial relationships, personal identity, and even the disruption of coping strategies previously accessed by personal R/S (Koenig, 2009). In individuals who happen to already have high amplitude resting alpha, there could be a degradation in the rhythm itself, as well as in restorative effects normally derived from relaxed wakefulness, meditation or prayer. It is even possible that the context of the assessments, being part of a longitudinal study within families, could rekindle old conflicts or stress in some individuals.

The twice verified association of early $\mathrm{R} / \mathrm{S}$ importance with alpha is more complex. Even though denomination change could contribute to the timecourse of alpha, particularly for some migrators, it is not sufficient to explain the unique relevance of the R/S assessment at T10. This problem prompts a fundamental question about $\mathrm{R} / \mathrm{S}$ importance: What is special about T10? The difference cannot be the age of the participant, because each of the groups contain participants of comparable ages. It also cannot be linked to individual differences, because the two studies were made up of largely independent samples. One possible explanation is that the question, "How important is religion or spirituality to you?," has changed its meaning or selectivity over time.

Local or cultural changes in the practice of, or attitude about, $\mathrm{R} / \mathrm{S}$ may correspond to the increasing trend in the United States to self-identify as "spiritual but not religious. This trend could itself have been further distorted in the T20 assessment, owing to their administration after the 9/11 terrorist attacks in New York City, the aftermath of which included higher rates of distress reactions (Stein et al., 2004). In one religious sample, most respondents reported feeling a closer connection to God or significant others (Meisenhelder \& Marcum, 2009), although those with higher stress or perceived threat engaged in multiple coping mechanisms. Conversely, the impact of political divisiveness, warfare and perceived religious extremism of all forms could result in an 'overloaded' question for many individuals. It is likewise unclear how the now ubiquitous engagement with hand-held technology might affect resting state brain activity and informal $\mathrm{R} / \mathrm{S}$ practice by competing for the time required for contemplative silence.

\subsection{Limitations of $R / S$ importance item}

The R/S importance item was chosen over twenty years ago as a brief measure suitable to the time-constraints of the participants in the ongoing longitudinal study of familial risk for MDD, but still likely to distinguish meaningful differences (cf. Miller et al., 1997, 2012). It has also proven to be able to distinguish groups that differ in brain structure (Miller et al., 2014), function (Peterson et al., 2014; Svob, Wang, Weissman, Wickramaratne, \& Posner, 2016), and EEG (Tenke et al., 2013). The present report affirms the original EEG findings using stronger measures, and unambiguously characterizes posterior EEG alpha as the biomarker identified by $\mathrm{R} / \mathrm{S}$ importance. However, all of these studies are limited by their reliance on this single item, which conflates religion and spirituality.

Pargament (1999) noted that while religion has traditionally provided the essential context for spirituality, a growing number of people identify as "spiritual, but not religious." The constructs of religion and spirituality have not only been changing over time, both in the psychological literature and the broader culture, but they have become pitted against each other, as the institutional vs. the individual, or even the "bad" vs. the "good." of particular importance to investigations of the relationship between $R / S$ and physical or mental health, he observed, "Many definitions of spirituality are in fact definitions of spiritual well-being." Koenig (2008) pressed this concern even further, noting that some measures confound spirituality and mental health, leading to tautological results that are easily misunderstood by readers and reviewers unfamiliar with the test instruments.

We identified trait-like differences in posterior resting alpha based on the R/S importance measure at a critical period in the ontogenesis of R/S. These differences parallel those anticipated from the presumed protective role of $\mathrm{R} / \mathrm{S}$ against MDD, raising the possibility that it may in some way be a proxy for mental health. Although our $\mathrm{R} / \mathrm{S}$ importance measure does not explicitly confound spirituality and mental health, the way the question is interpreted by study participants will nevertheless be influenced by the ongoing drift in the meaning of these terms. It is hoped that a better understanding of the religious and spiritual characteristics of these participants, such as those provided by a new battery of more refined measures ${ }^{2}$ in our ongoing work, will provide a clearer characterization of the $\mathrm{R} / \mathrm{S}$ importance groupings and the assortment of these groupings by EEG alpha.

\section{Disclosure}

Drs. Tenke, Kayser, Warner, Wickramaratne and Bruder, Mr. Alvarenga, and Ms. Abraham have no disclosures to make. Dr. Svob has received funding from the Templeton Foundation, and Dr. Miller has received funding from the Templeton Foundation,

\footnotetext{
2 Our ongoing follow-up study employs a multifaceted survey covering various religiosity (i.e., religious identity, religious commitment, religious engagement, personal relationship with God, intrinsic religiosity, religious coping, support derived from a religious community) and spiritual measures (i.e., gratitude, compassion, forgiveness, self-transcendence, ecological awareness, mind-body practices, altruism, love).
} 
the Klingenstein Fund, and the Pritchard Foundation, and received payment from Oxford University Press. Dr. Weissman has received funding from NIMH, the National Institute on Drug Abuse (NIDA), NARSAD, the Sackler Foundation, the Templeton Foundation, and the Interstitial Cystitis Association, and receives royalties from Oxford University Press, Perseus Books, American Psychiatric Association Press, and MultiHealth Systems.

\section{Acknowledgments}

Supported by the John Templeton Foundation. The data collection was funded by NIMH grant MH36197, and the CSD methods by MH36295.

\section{Appendix A. Supplementary data}

Supplementary data associated with this article can be found, in the online version, at http://dx.doi.org/10.1016/j.biopsycho.2017. 01.005 .

\section{References}

Aftanas, L., \& Golosheykin, S. (2005). Impact of regular mediatation practice on EEG activity at rest and during evoked negative emotions. International Journal of Neuroscience, 115, 893-909.

Alschuler, D. M., Tenke, C. E., Bruder, G. E., \& Kayser, J. (2014). Identifying electrod bridging from electrical distance distributions: a survey of publicly-available EEG data using a new method. Clinical Neurophysiology, 125, 484-490.

Bendat, J. S., \& Piersol, A. G. (1971). Random data: analysis and measurement procedures. New York, NY: Wiley-Interscience.

BioSemi, Inc. (2001). ActiveTwo-Multichannel, DC amplifier, 24-bit resolution, biopotential measurement system with active electrodes (http://www.biosemi.com). Amsterdam,NL: Author.

Bruder, G. E., Fong, R., Tenke, C. E., Leite, P., Towey, J. P., Stewart, J. E., et al. (1997). Regional brain asymmetries in major depression with or without an anxiety disorder: a quantitative EEG study. Biological Psychiatry, 41, 939-948.

Bruder, G. E., Tenke, C. E., Warner, V., Nomura, Y., Grillon, C., Hille, J., et al. (2005). Electroencephalographic measures of regional hemispheric activity in offspring at risk for depressive disorders. Biological Psychiatry, 57, 328-335.

Bruder, G. E., Sedoruk, J. P., Stewart, J. W., McGrath, P. J., Quitkin, F. M., \& Tenke, C. E. (2008). Electroencephalographic alpha measures predict therapeutic response to a selective serotonin reuptake inhibitor antidepressant: pre- and post-treatment findings. Biological Psychiatry, 63, 1171-1177.

Cahn, B. R., \& Polich, J. (2006). Meditation states and traits: EEG, ERP, and neuroimaging studies. Psychological Bulletin, 132, 180-211.

Chiesa, A., \& Serretti, A. (2010). A systematic review of neurobiological and clinical features of mindfulness mediations. Psychological Medicine, 40, 1239-1252.

Flannelly, K. J., Koenig, H. G., Galek, K., \& Ellison, C. G. (2007). Beliefs, mental health: and evolutionary threat assessment systems in the brain. Journal of Nervous and Mental Disorders, 195, 996-1003.

Gloor, P. (1969). Hans Berger and the discovery of the electroencephalogram. Electroencephalography and Clinical Neurophysiology, Supplement, 28, 1-36.

Henriques, J. B., \& Davidson, R. J. (1990). Regional brain electrical asymmetries discriminate between previously depressed and healthy control subjects. Journal of Abnormal Psychology, 99, 22-31.

Idler, E. L., Musick, M. A., Ellison, C. G., George, L. K., Krause, N., Ory, M. G., et al (2003). Measuring multiple dimensions of religion and spirituality for health research: conceptual background and findings from the 1998 General Social Survey. Research on Aging, 25, 327-365.

Jacobs, M., Miller, L., Wickramaratne, P., Gameroff, M., \& Weissman, M. M. (2012). Family religion and psychopathology in children of depressed mothers: ten-year follow-up. Jounal of Affective Disorders, 136, 320-327.

Jurcak, V., Tsuzuki, D., \& Dan, I. (2007). 10/20, 10/10: and 10/5 systems revisited: Their validity as relative head-surface-based positioning systems. NeuroImage, 34, 1600-1611

Kayser, J., \& Tenke, C. E. (2003). Optimizing PCA methodology for ERP component identification and measurement: theoretical rationale and empirical evaluation. Clinical Neurophysiology, 114, 2307-2325.

Kayser, J., \& Tenke, C. E. (2006). Principal components analysis of Laplacian waveforms as a generic method for identifying ERP generator patterns: I. Evaluation with auditory oddball tasks. Clinical Neurophysiology, 117, 348-368.

Kayser, J., Tenke, C.E., (2006b). Electrical distance as a reference-free measure for identifying artifacts in multichannel electroencephalogram (EEG) recordings. Psychophysiology, [43,] S51 (http://psychophysiology.cpmc.columbia.edu/ mmedia/spr2006/ElecDistArti.pdf).

Kayser, J., \& Tenke, C. E. (2015a). Issues and considerations for using the scalp surface Laplacian in EEG/ERP research: a tutorial review. International Journal of Psychophysiology, 97, 189-209.
Kayser, J., \& Tenke, C. E. (2015b). Hemifield-dependent N1 and event-related theta/delta oscillations: an unbiased comparison of surface Laplacian and common EEG reference choices. International Journal of Psychophysiology, 97, $258-270$.

Kayser J. (2009) Current Source Density (CSD) Interpolation using Spherical Splines: CSD Toolbox, Available at: <http://psychophysiology.cpmc.columbia. edu/Software/CSDtoolbox>.

Kendler, K. S., Gardner, C. O., \& Prescott, C. A. (1997). Religion, psychopathology, and substance use and abuse; a multimeasure, genetic-epidemiologic study. American Journal of Psychiatry, 154, 322-329.

Klimesch, W. (1999). EEG alpha and theta oscillations reflect cognitive and memory performance: a review and analysis. Brain Research Reviews, 29, 169-195.

Koenig, H. G., McCullough, M. E., \& Larson, D. B. (2001). Handbook of religion and health. New York, Oxford: University Press.

Koenig, H. G. (2008). Concerns about measuring spirituality in research. The Journal of Nervous and Mental Disease, 196, 349-355.

Koenig, H. G. (2009). Research on religion, spirituality, and mental health: A review. Canadian Journal of Psychiatry, 54, 283-291.

Larson, D. B., \& Larson, S. S. (2003). Spirituality ‘s potential relevance to physical and emotional health: a brief review of quantitative research. Journal of Psychology and Theology, 31, 37-51.

Meisenhelder, J. B., \& Marcum, J. P. (2009). Terrorism, post-traumatic stress, coping strategies, and spiritual outcomes. Journal of Religion and Health, 48, 46-57.

Miller, L., Warner, V., Wickramaratne, P., \& Weissman, M. (1997). Religiosity and depression: ten-year follow-up of depressed mothers and offspring. Journal of the American Academy of Child and Adolescent Psychiatry, 36, 1416-1425.

Miller, L., Wickramaratne, P., Gameroff, M. J., Sage, M., Tenke, C. E., \& Weissman, M M. (2012). Religiosity and major depression in adults at high risk: A ten-year prospective study. American Journal of Psychiatry, 169, 89-94

Miller, L., Bansal, R., Wickramaratne, P., Xoa, X., Tenke, C. E., Weissman, M. M., et al. (2014). Neuroanatomical correlates of religiosity and spirituality in adults at high and low familial risk for depression. JAMA Psychiatry, 71, 128-135.

NeuroScan, Inc. (2003). SCAN 4.3 - vol. II. EDIT 4.3 - offline analysis of acquired data (Document number 2203, revision D). El Paso, TX: Compumedics Neuroscan.

Pargament, K. I. (1999). The psychology of religion and spirituality? Yes and no. The International Journal for the Psychology of Religion, 9, 3-16.

Perrin, F., Pernier, J., Bertrand, O., \& Echallier, J. F. (1989). Spherical splines for scalp potential and current density mapping. Electroencephalography and Clinical Neurophysiology, 72, 184-187 [Corrigenda EEG 02274, EEG clin Neurophysiol 1990, 76, 565]

Peterson, B. S., Wang, Z., Horga, G., Warner, V., Rutherford, B., Klahr, K. W., et al (2014). Discriminating risk and resilience endophenotypes from lifetime illness effects in familial major depressive disorder. JAMA Psychiatry, 71, 136-148.

Pivik, R. T., Broughton, R. J., Coppola, R., Davidson, R. J., Fox, N., \& Nuwer, M. R. (1993). Guidelines for the recording and quantitative analysis of electroencephalographic activity in research contexts. Psychophysiology, 30, 547-558.

Smith, T. B., McCullough, M. E., \& Poll, J. (2003). Religiousness and depression: evidence for a main effect and the moderating influence of stressful life events. Psychological Bulletin, 129, 614-636.

Stein, B. D., Elliott, M. N., Jaycox, L. H., Collins, R. L., Berry, S. H., Klein, D. J., et al. (2004). A national longitudinal study of the psychological consequences of the September 11, 2001 terrorist attacks: reactions, impairment and help-seeking. Psychiatry, 67, 105-117.

Svob, C., Wang, Z., Weissman, M. M., Wickramaratne, P., \& Posner, J. (2016) Religious and spiritual importance moderate relation between default mode network connectivity and familial risk for depression. Neuroscience Letters, 634 94-97.

Tenke, C. E., \& Kayser, J. (2001). A convenient method for detecting electrolyte bridges in multichannel electroencephalogram and event-related potential recordings. Clinical Neurophysiology, 112, 545-550.

Tenke, C. E., \& Kayser, J. (2005). Reference-free quantification of EEG spectra: combining current source density (CSD) and frequency principal components analysis (fPCA). Clinical Neurophysiology, 116, 2826-2846.

Tenke, C. E., \& Kayser, J. (2015). Surface Laplacians (SL) and phase properties of EEG rhythms: simulated generators in a volume-conduction model. International Journal of Psychophysiology, 97, 285-298.

Tenke, C. E., Kayser, J., Manna, C. B. G., Fekri, S., Kroppmann, C. J., Schaller, J. D., et al. (2011). Current source density measures of EEG alpha predict antidepressant treatment response. Biological Psychiatry, 70, 388-394

Tenke, C. E., Kayser, J., Miller, L., Warner, V., Wickramaratne, P., Weissman, M. M. et al. (2013). Neuronal generators of posterior EEG alpha reflect individual differences in prioritizing personal spirituality. Biological Psychology, 94, 426-432.

Tenke, C. E., Kayser, J., Abraham, K., Alvarenga, J. E., \& Bruder, G. E. (2015). Posterior EEG alpha at rest and during task performance: comparison of current source density and field potential measures. International Journal of Psychophysiology, 97, 299-309.

Tenke, C.E., Kayser, J., Alvarenga, J.E., Abraham, K., Warner, V., Weissman, M.M. Bruder, G.E. (submitted). Stability of EEG measures over ten years in offspring at risk for depressive disorders.

Tsuang, M. T., Williams, W. M., Simpson, J. C., \& Lyons, M. J. (2002). Pilot study of spirituality and mental health in twins. American Journal of Psychiatry, 159, 486-488.

Ulrich, G., Renfordt, E., \& Frick, K. (1986). The topographical distribution of alpha-activity in the resting EEG of endogenous-depressive inpatients with 
and without clinical-response to pharmacotherapy. Pharmacopsychiatry, 19 , 272-273.

Weissman, M. M., Warner, V., Wickramaratne, P., Moreau, D., \& Olfson, M. (1997) Offspring of depressed parents: ten years later. Archives of General Psychiatry, 54, 932-940.

Weissman, M. M., Wickramaratne, P., Nomura, Y., Warner, V., Verdeli, H., Pilowsky, D. J., et al. (2005). Families at high and low risk for depression: a 3-generation study. Archives of General Psychiatry, 62, 29-36.
Weissman, M. M., Wickramaratne, P., Nomura, Y., Warner, V., Pilowsky, D., \& Verdeli, H. (2006). Offspring of depressed parents: 20 years later. American Journal of Psychiatry, 163, 1001-1008.

Weissman, M. M., Berry, O. O., Warner, V., Gameroff, M. J., Skipper, J., Talati, A. et al. (2016). A 30-year study of 3 generations at high risk and low risk for depression. JAMA Psychiatry, 73, 970-977.

Weissman, M. M., Wickramaratne, P., Gameroff, M. J., Warner, V., Pilowsky, D. Kohad, R. G., et al. (2016). Offspring of depressed parents : 30 years later. American Journal of Psychiatry, 173, 1024-1032. 